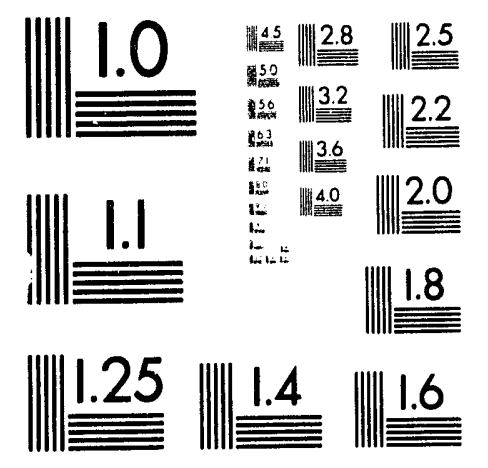



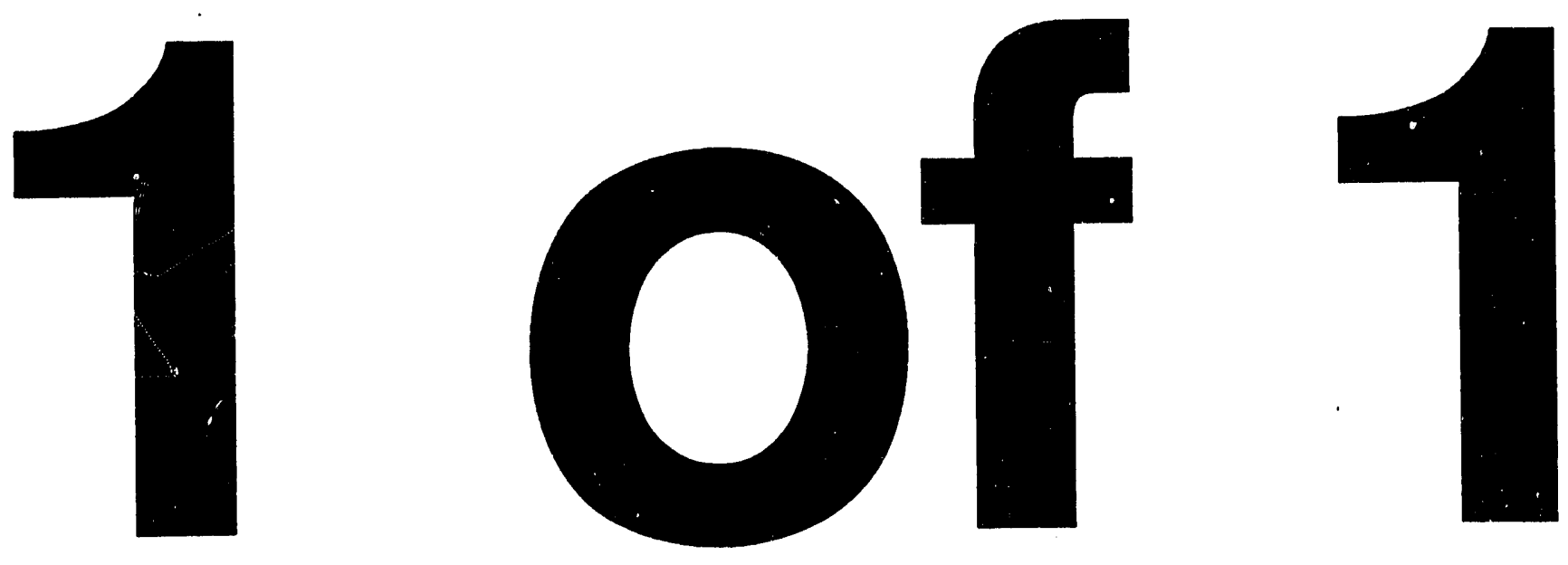


\title{
Physics Design Requirements for the Tokamak Physics Experiment (TPX)
}

\author{
G. H. Neilson'1 R. J. Goldston, S. C. Jardin, W. M. Nevins' \\ M. Porkolab 3 , W. T. Reiersen, and M. Ulrickson ${ }^{4}$ \\ Princeton Plasma Physics Laboratory \\ P. O. Box 451, Princeton, New Jersey 08543
}

\begin{abstract}
The design of TPX is driven by physics requirements that follow from its mission. The tokamak and heating systems provide the performance and profile controls needed to study advanced steady state tokamak operating modes. The magnetic control systems provide substantial flexibility for the study of regimes with high beta and bootstrap current. The divertor is designed for high steady state power and particle exhaust.
\end{abstract}

\section{INTRODUC'TION}

The mission of the Tokamak Physics Experiment (TPX) is to develop the scientific basis for a compact and continuously operating tokamak fusion reactor. Recent

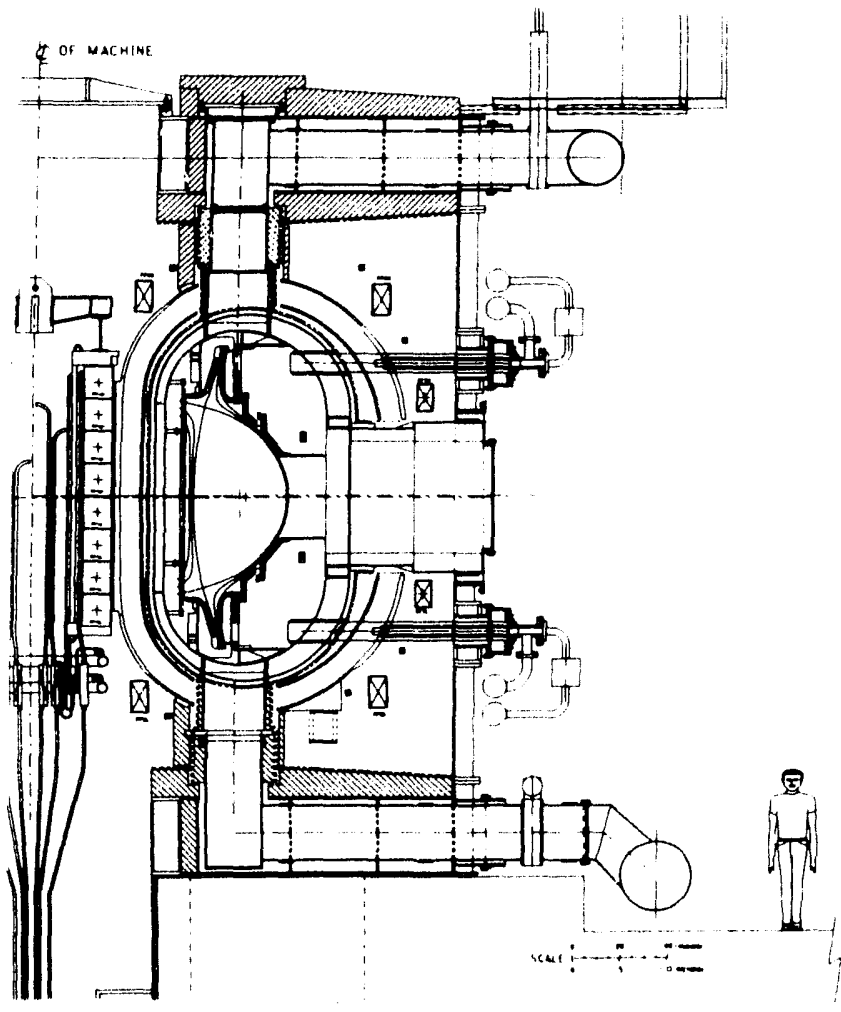

Figure 1. Elevation view of TPX.

1 Oak Ridge National Laboratory, Oak Ridge, TN 37831.

2 Lawrence Livermore National Laboratory, Livermore, CA 94550.

3 Massachusetts Institute of Technology, Cambridge, MA 02139.

4 Current address: Sandia National Laboratories, Albuquerque, NM 87185.

Manuscript received October 14, 1993. Work supported by U.S. DOE Contract No. DE-AC02-76CH0307 with Princeton Plasma Physics Laboratory. reactor optimization studies [1] show that steady state operation and tokamak physics improvements relative to the present data base are the keys to achieving this mission. These improvements include the achievement of beta values significantly above the Troyon limit, confinement times significantly above $\mathrm{H}$-mode scaling, efficient current drive by taking advantage of the bootstrap current, advanced power and particle exhaust, and high reliability. The planned approach is to use steady state plasma controls, particularly control of the current profile, to attain these improvements. This paper provides an overview of the physics requirements that drive the design of this facility.

\section{MAJOR PARAMETERS}

\section{A. Tokamak}

The major parameters of the baseline TPX facility, shown in Fig. 1, are summarized in the "Baseline" column of Table I. The toroidal field, plasma current, and size provide sufficient performance, in deuterium plasmas, for advanced tokamak physics studies. The tokamak is designed with no inherent limitations on pulse length, however the baseline facility with ancillary systems provides a pulse length of $1,000 \mathrm{~s}$. This is ample for current-profile equilibration and significantly longer than the pulse lengths that existing high-power divertor tokamaks (e.g., DIII-D, JET, JT-60U, ASDEX-U) will achieve. Plaisma-wall equilibration times are more difficult to predict; it is not even clear whether the wall will saturate in long-pulse operation with active pumping. In the future, the pulse length can be extended for plasma reliability studies beyond $1,000 \mathrm{~s}$ by removing the limits imposed by external systems, such as cryopumping and cooling capacities.

Table I

TPX Machine Parameters

\begin{tabular}{|c|c|c|c|}
\hline & Baseline & Upgrade & \\
\hline Toroidal field, $\mathrm{B}_{\mathrm{T}}$ & 4.0 & & $\mathrm{~T}$ \\
\hline Plasma Current, IP & 2.0 & & MA \\
\hline Pulse length & 1,000 & $>>1,000$ & $\mathbf{s}$ \\
\hline Major radius, $R_{0}$ & 2.25 & & m \\
\hline Minor rudius, a & 0.50 & & m \\
\hline Aspect ratio, $\mathrm{R} / \mathrm{a}$ & 4.5 & & \\
\hline Elongation, $\kappa_{\mathbf{x}}$ & 2.0 & & \\
\hline Triangularity, $\delta_{X}$ & 0.8 & & \\
\hline Neutral beams, $\mathrm{P}_{\mathrm{NB}}$ & 8 & 24 & MW \\
\hline ICRF, PIC & 8 & 18 & MW \\
\hline Lower hybrid, $\mathrm{P}_{\mathrm{LH}}$ & 1.5 & 3.0 & MW \\
\hline Electron cyclotron, $\mathrm{P}_{\mathrm{EC}}$ & & 10 & MW \\
\hline DD neutron budget & $6 \times 10^{21}$ & & $\mathrm{yr}^{-1}$ \\
\hline Peak DD neutron rate & $5 \times 10^{16}$ & $1.0 \times 10^{17}$ & $\mathbf{s}^{-1}$ \\
\hline
\end{tabular}


The advanced tokamak mission places special requirements on the plasma geometry. High values of elongation and iriangularity were chosen because MHD stability theory and most experiments [2] indicate that a strongly shaped cross section with a double-null (DN) poloidal divertor is optimum for advanced plasma performance. The DN configuration minimizes the heat loads to the inboard divertor targets, allowing an open configuration there. The outboard divertor is arranged in a slot configuration to support radiative target operation and handle the heat loads associated with up to $45 \mathrm{MW}$ of heating power. The choice of the aspect ratio $\mathrm{R}_{0} / \mathrm{a}$ of 4.5 was motivated by reactor studies $[3,4]$ that have found potentially attractive design points at aspect ratios in this range, where the bootstrap current substantially reduces auxiliary current drive requirements. The TPX will greatly expand the tokamak physics data base in the high aspect ratio regime.

\section{B. Heating and Current Drive Systems}

The TPX heating and current drive system serves several purposes: to heat the plasma to high temperature and normalized beta, to supplement the bootstrap contributions to the steady-state toroidal plasma current, and to control the plasma current profile. The TPX system is based on multiple technologies (neutral beams, ICRF, and lower hybrid) to best serve these diverse purposes and to provide an important element of plasma control flexibility. Initially, a total of $17.5 \mathrm{MW}$ is provided, but the power can be increased to the levels indicated in the "Maximum" column of Table I.

Neutral beams provide efficient current drive, ion heating, core fueling, toroidal momentum drive, and serve a particle source for key diagnostics. Initially $8 \mathrm{MW}$ will be injected tangentially at a maximum energy of $120 \mathrm{keV}$ in deuterium.

The Ion Cyclotron Range of Frequencies (ICRF) system provides electron or ion heating and centrallypeaked current drive in the $40-80 \mathrm{MHz}$ frequency range. The initial system will provide $8 \mathrm{MW}$, coupled through a 12 strap antenna array. The phasing will be variable in real time between heating-only and current-drive operation.

The lower hybrid system provides off-axis current profile control, efficient bulk current drive at low temperature, and electron heating. A waveguide-grill launcher will provide $1.5 \mathrm{MW}$ to the plasma at a frequency of $3.7 \mathrm{GHz}$. The spectrum is variable for profile control flexibility. The launcher is movable over a $5 \mathrm{~cm}$ range in real time for coupling under changing plasma conditions.

\section{PERFORMANCE}

\section{A. Criteria}

The performance of TPX is set by criteria for advanced physics studies. To make the bootstrap current profile in TPX be representative of a reactor, the collisionality must be low enough that the total bootstrap current is reduced by less than $15 \%$ from its collisionless value (i.e., $\Delta f_{B S}<0.15$ ). To ensure effective current profile control the fast electrons used for lower-hybrid current drive must be well localized. If that the diffusivity of fast electrons is comparable to the bulk electrion thermal diffusivity, an assumption confirmed by experimental results [5,6], this criterion sets a limit on $\tau_{\mathrm{se}} / \tau_{\mathrm{E}}$ (where $\tau_{\mathrm{se}}$ is the fast electron slowing-down time). To obtain reasonably well localized current drive we require $\tau_{\mathrm{sc}} / \tau_{\mathrm{E}} \leq 0.13$.

The major parameters of TPX have been chosen to satisfy the collisionality and fast-electron-confinement critera over a wide density range. Here we assume that the confinement time scales as the square root of the atomic mass. Under this assumption the size and/or magnetic field, as well as the heating power, of a hydrogen-only device would have to be substantially increased relative to TPX to have the same advanced-tokamak performance. More fundamentally, however, enhanced confinement modes are in practice more reliably obtained in deuterium than in hydrogen. Thus the ability to operate substantially in deuterium is a key requirement.

\section{B. Operating Points}

In developing TPX operating points we have generally employed a zero-D model based on ITER physics rules [7]. We have adopted a more accurate bootstrap current model, used MHD beta limits consistent with kink and ballooning mode calculations for specific operating modes, and assumed confinement enhancement factors (H) over L-mode scaling in excess of 2 where noted. With the baseline heating and current drive system it will be possible to meet minimum experimental objectives for enhanced beta values and high bootstrap fraction if confinement is moderately favorable, i.e. $\mathrm{H} \geq 3$, as seen transiently in present tokamak experiments. Representative operating modes are illustrated in Table II.

Case A: 2 MA High-beta Operation. Full-current deuterium discharges can be maintained with the baseline heating system by combining density control with enhanced confinement operation. This projected operating point reaches the first-stable (Troyon) beta limit at full current (2 MA) and full magnetic field (4 T).

Case B: High Bootstrap Operation. This case illustrates

Table II

TPX Operating Modes in Deuterium

\begin{tabular}{lcccc}
\hline Case & A & B & C & \multicolumn{1}{l}{ D } \\
\hline Toroidal field, $\mathrm{B}_{\mathrm{T}}(\mathrm{T})$ & 4.0 & 4.0 & 4.0 & 4.0 \\
Plasma Current, IP (MA) & 2.0 & 1.4 & 1.2 & 2.0 \\
NBI power, $\mathrm{P}_{\mathrm{NB}}(\mathrm{MW})$ & 8.0 & 8.0 & 8.0 & 16.0 \\
ICRF power, $\mathrm{P}_{\mathrm{IC}}(\mathrm{MW})$ & 8.0 & 8.0 & 8.0 & 12.0 \\
$\mathrm{LH}$ power, $\mathrm{P}_{\mathrm{LH}}(\mathrm{MW})$ & 1.5 & 1.5 & 1.5 & 1.5 \\
$\mathbf{q 9 5}$ & 3.3 & 5.0 & 4.5 & 3.4 \\
$\beta_{\mathrm{N}}(\%-\mathrm{m}-\mathrm{T} / \mathrm{MA})$ & 3.1 & 3.3 & 4.0 & 5.5 \\
$\mathrm{f}_{\mathrm{BS}}$ & 0.42 & 0.72 & 0.54 & 0.73 \\
$\mathrm{H}$ factor, $\tau_{\mathrm{E}} / \tau_{\mathrm{L}}$ & 3 & 3 & 3 & 4 \\
$\mathrm{n}_{\mathrm{e} 0}\left(10^{20} \mathrm{~m}^{-3}\right)$ & 0.94 & 1.3 & 1.0 & 1.3 \\
$\mathrm{~T}_{\mathrm{e} 0}(\mathrm{keV})$ & 18.3 & 9.4 & 9.9 & 20.6 \\
$\mathrm{~T}_{\mathrm{i} 0}(\mathrm{keV})$ & 18.9 & 9.4 & 9.7 & 22.9 \\
$\mathrm{DD}$ neutrons $\left(10^{16} \mathrm{~s}^{-1}\right)$ & 3.8 & 1.8 & 1.3 & 12.0 \\
$\Delta \mathrm{f}_{\mathrm{BS}}-$ collisionality & 0.01 & 0.12 & 0.05 & 0.01 \\
$\tau_{\mathrm{se}} / \tau_{\mathrm{E}}$ & 0.01 & 0.01 & 0.01 & \\
\hline
\end{tabular}


high-bootstrap operation near the Troyon limit at reduced plasma current with the baseline heating system. The density $\left.\left(<\mathrm{n}_{\mathrm{e}}\right\rangle=0.75 \times 10^{20} \mathrm{~m}^{-3}\right)$ should correspond to favorable divertor operation.

Case C.Enhanced beta Operation. In this case the Troyon beta limit is substantially exceeded by reducing the magnetic field to $3.3 \mathrm{~T}$. Hence, the initial current drive and heating system will provide sufficient power to test beat limits at substantial magnetic fields if we can achieve $\mathrm{H} \approx 3$ confinement performance.

Case D: Enhanced Performance Operation. This case takes advantage of heating upgrades to $-30 \mathrm{MIW}$ and enhanced confinement $(\mathrm{H}=4)$ to achieve beta limits and bootstrap fractions that meet TPX goals at full performance. Magnetohydrodynamic stability studies confirm the existence of stable configurations at this beta value with specially shaped current profiles that closely match the bootstrap profile.

Basic Operation. Steady-state discharges can be maintained in hydrogen (at $I P=1 \mathrm{MA}$ ) and deuterium (1.5-MA) under more conservative assumptions $(\mathrm{H}=2)$. These would satisfy the performance criteria and permit substantial progress on TPX objectives. During the first two years deuterium operation will be limited to avoid activating the machine beyond the limit for in-vessel hands-on maintenance.

\section{MAGNETIC CONTROLS}

\section{A. Equilibrium Control}

Although the TPX tokamak is designed for steady state operation, the poloidal field (PF) system supports a conventional inductive plasma initiation with a loop voltage up to $20 \mathrm{~V}$. It provides about 18 volt-seconds to inductively raise the current to $2 \mathrm{MA}$ and to then sustain an inductively-driven flattop for $\sim 10$ seconds. The standard

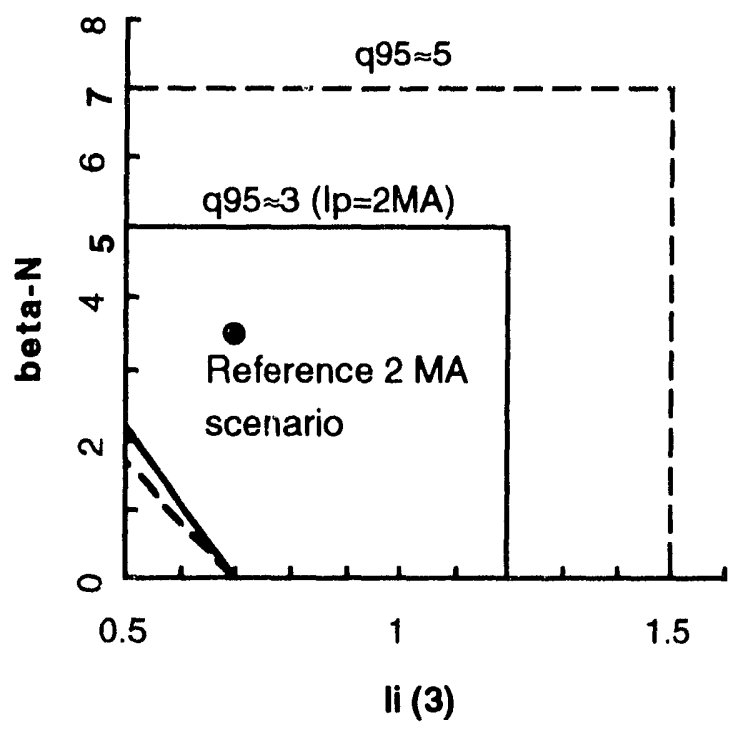

Figure 2. Schematic of required TPX equilibrium operating space. flattop condition is a double-null diverted discharge with $\beta_{N}=3.5, l_{i}(3)=0.7, \kappa_{x}=2.0$, and $\delta_{x}=0.8$. These conservative startup requirements ensure a reliable access to conditions compatible with steady-state operation.

An important requirement for advanced tokamak studies is a PF system that provides substantial flexibility in the range of equilibrium shapes and profiles. The required operating space is illustrated in Fig. 2. The lowbeta, low- $l_{i}$ region is excluded due to limited interest and difficulties with vertical stability. The plasma shape is not fixed throughout this space, but varies in order to keep the scrapeoff plasma focussed onto the high-heat-flux divertor targets. Single-null operation is also available.

\section{B. Position Control}

Careful control of the plasma shape and position is essential to the successful operation of TPX. The gap between the edge of the plasma and internal components is $\sim 2 \mathrm{~cm}$, and the plasma shape must adjust to changing equilibrium conditions in order to interface properly with the divertor. In addition, position control is required to maintain good coupling with the ICRF launchers. The TPX will maintain control of the plasma's radial position, the vertical position, and the outer strike point within $\pm 1 \mathrm{~cm}$ of their nominal positions.

Control of the vertical instability is critical because of the highly elongated plasmas in TPX. The two key design features for this are passive structure and active control coils. The passive structure consists of toroidal conductors close to the plasma on both the inboard and outboard side. In order to satisfy passive stabilization criteria over the widest possible operating space, the stabilizers have been designed to be as close to the plasma as possible, and to span as large a poloidal angle as possible. Active vertical control on fast time scales is provided by a pair of coils located betwe 1 the passive structure and the vacuum vessel. The in-vessel location is necessary to prevent inductive heating of the cold-structure by the fluctuating control currents.

\section{Control of Non-axisymmetric Perturbations}

A class of attractive operating modes with high bootstrap current fractions and beta well above the Troyon limit imposes special design requirements to deal with external kink modes. These are pressure-driven nonaxisymmetric MHD instabilities associated with high edge current densities. Experimentally and theoretically, it is found that a complete conducting shell surrounding the plasma at an average minor radius of about $1.3 \mathrm{a}$ is necessary to stabilize these modes. The TPX vacuum vessel is too far from the plasma to meet this criterion, so special requirements are imposed on the passive structure in addition to those for vertical position control. While the TPX structure does not provide complete coverage in toroidal and poloidal angle, this is partially offset by its being much closer to the plasma than 1.3a. Narrow vertical conductors connecting the upper and lower toroidal stabilizers provide a current path for quasi-helical eddy currents needed to stabilize the external kink mode. In addition, the toroidal stabilizers themselves are widened wherever possible without interfering with heating system penetrations. This three-dimensional "cage" passive structure design is illustrated in Figure 3. 

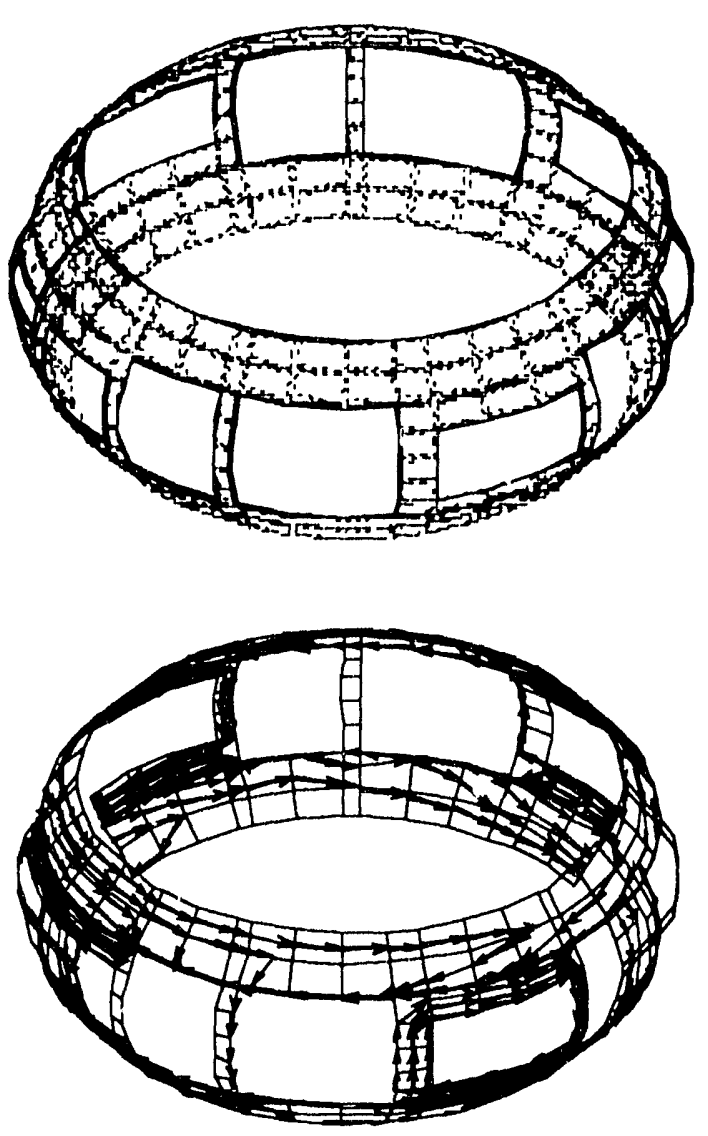

Figure 3. Flexible cage design concept for outboard passive structure to stabilize vertical and external kink modes.

The passive structure alone may be sufficient to stabilize the kink modes, provided the modes maintain a high toroidal phase velocity with respect to the structure. The tangential, co-injected neutral beams promote such rotation. Since mode locking due to field errors can arrest rotation, an external modular coil system for quasi-static field error compensation is provided. An additional feature being considered is to also incorporate internal modular coils for active feedback control. This would provide a further margin of safety; however, the requirement for this capability remains to be determined.

\section{DIVERTOR}

\section{A. Power Handling}

The plasma-facing components are designed to handle the maximum steady state heating power of $45 \mathrm{MW}$. This corresponds to an average heat flux across the separatrix of $0.75 \mathrm{MW} / \mathrm{m}^{2}$, which is what must be handled in a reactor with a neutron wall load of $3 \mathrm{MW} / \mathrm{m}^{2}$. The divertor targets are designed to the "technology limit" for power handling, about $15 \mathrm{MW} / \mathrm{m}^{2}$. This enables them to handle the $18 \mathrm{MW}$ of heating power included in the project baseline, under standard divertor physics models with conservative safety factors. The experimental data base suggests that standard divertor operation may accommodate even more power than $18 \mathrm{MW}$, but dispersive approaches are almost certainly required to accommodate the maximum $45 \mathrm{MW}$.

\section{B. Particle Handling}

The divertor pumping system is required to exhaust the maximum main-plasma particle throughput $\left(5 \times 10^{21} \mathrm{~s}^{-1}\right)$ at a pressure of $1 \mathrm{mtorr}$. The required pumping speed of $85,000 \mathrm{l} / \mathrm{s}$ is achieved with external cryopumps connected to the divertor region through 16 large-diameter ducts. Gas target data from DIII-D [8] suggest that raising the pressure to 3 mtorr could lead to a 5 -fold reduction in peak heat fluxes. Gas injectors in the midplane and divertor regions provide flexibility in supplying additional fuel to the scrape-off plasma if needed to produce such conditions. For plenum pressures up to $10 \mathrm{mtorr}$, a variable aperture is installed in the pump ducts to reduce the pumping speed.

\section{Plasma-facing materials}

Carbon-based materials will be used for the divertor targets, as well as the baffles, limiters, and protective armor. Operating experience on most tokamaks in the last 15 years has consistently shown a strong preference for the use of low Z materials for optimum performance. Carbon is chosen over beryllium because of concerns about melting, especially during disruptions. Calculated net erosion rates for carbon divertors in TPX are about $100 \AA / \mathrm{s}$ for highperformance deuterium operation. This translates to acceptable lifetimes for the initial divertor. The TPX divertor is modular and remotely replaceable, so it can accommodate a changeover to alternative materials or configurations at a later time if desired.

\section{SUMMARY}

The physics requirements for TPX define a machine with an impressive experimental capability. These are now being implemented in the engineering design phase. When it becomes operational in 2000 TPX will be a unique facility for the development of economical, steady state fusion reactors.

\section{REFERENCES}

[1] L. J. Perkins, J. Galambos, S. Haney, J. Mandrekas, "The Impact of Improved Physics on Commercial Tokamak Reactors," to be submitted to Nuclear Fusion.

[2] E. A. Lazarus and the DIII-D Team, "Dependence of $\beta \bullet \tau$ on Plasma Shape in DIII-D," 20th EPS Conference on Controlled Fusion and Plasma Physics, July 26-30, 1993, Lisbon, Portugal; to be published in Proceedings.

[3] M. Kikuchi, Nucl. Fusion 30 (1990) 265.

[4] R. W. Conn, F. Najmabadi, et al., "ARIES-I, A Steady-State First-Stability Tokamak Reactor with Enhanced Safety and Environmental Features," 13th Int. Conference on Plasma Physics and Controlled Nuclear Fusion Research, Washington, DC, 1-6 October, 1990, paper IAEA-CN-53/H-1-4.

[5] S. Texter et al., Phys. Letters A 175 (1993) 428.

[6] R. Kaita et al., IAEA Würzburg, Germany, 1992. PBX-M post-deadline paper.

[7] N. A. Uckan et al., ITER Physics Design Guidelines: 1989, ITER Documentation Series No. 10 (IAEA, Vienna, 1990).

[8] T. Petrie et al., "Divertor Heat Flux Reduction by D2 Injection in DIII-D," Bull. Am Phys. Soc. 37 (1992) 1565 (abstract). 


\section{DISCLAIMER}

This report was prepared as an account of work sponsored by an agency of the United States Government. Neither the United States Government nor any agency thereof, nor any of their employees, makes any warranty, express or implied, or assumes any legal liability or responsibility for the accuracy, completeness, or usefulness of any information, apparatus, product, or process disciosed, or represents that its use would not infringe privately owned rights. Reference herein to any specific commercial product, process, or service by trade name, trademark, manufacturer, or otherwise does not necessarily constitute or imply its endorsement, recommendation, or favoring by the United States Government or any agency thereof. The views and opinions of authors expressed herein do not necessarily state or reflect those of the United States Government or any agency thereof. 

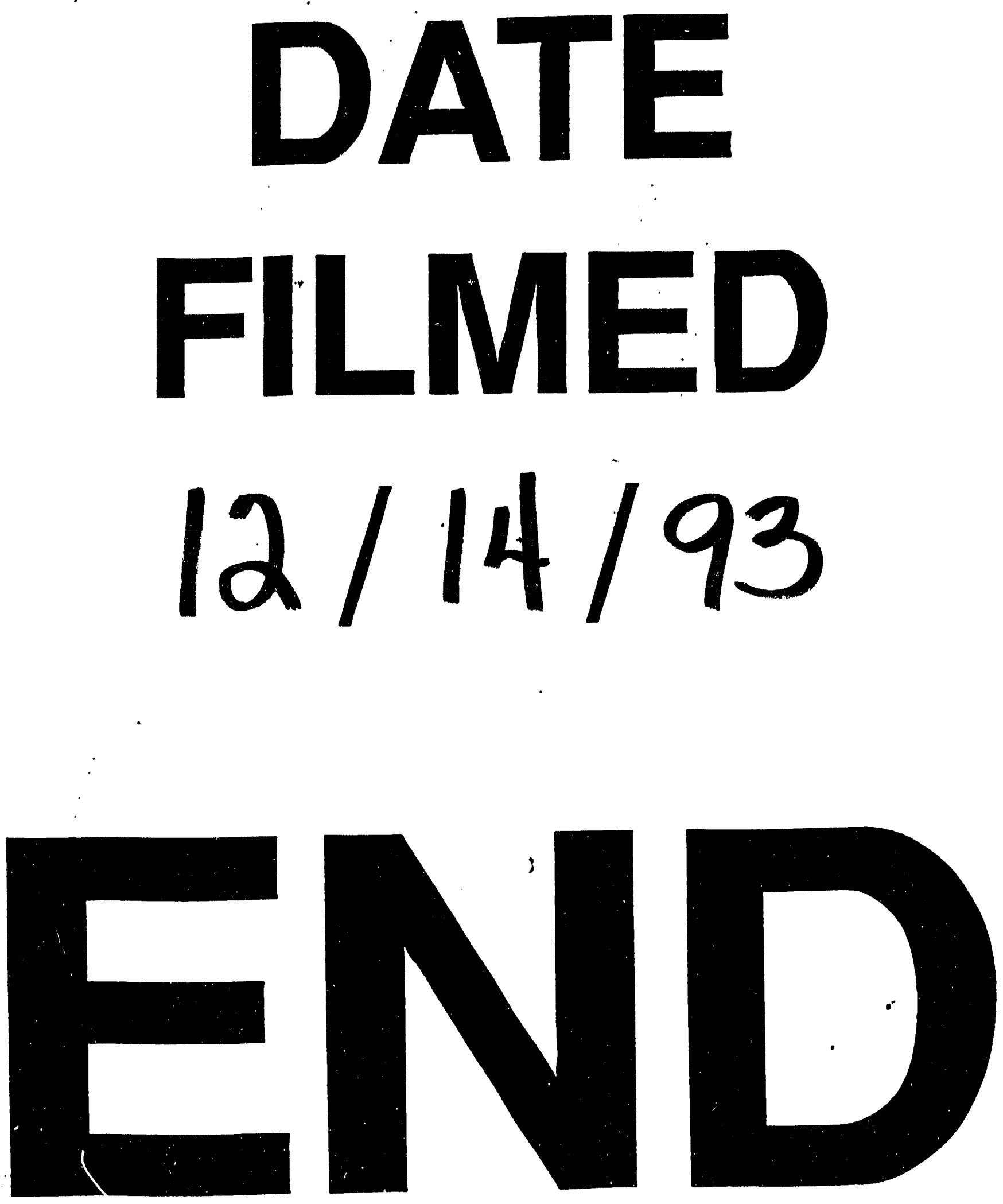


$$
\text { nam }
$$
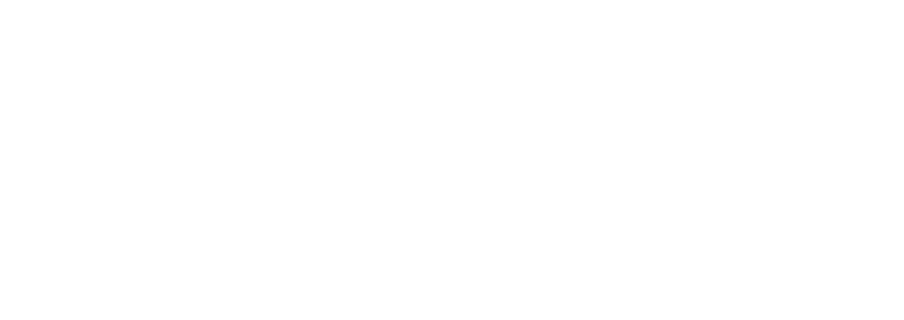

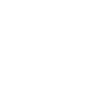

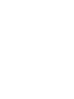
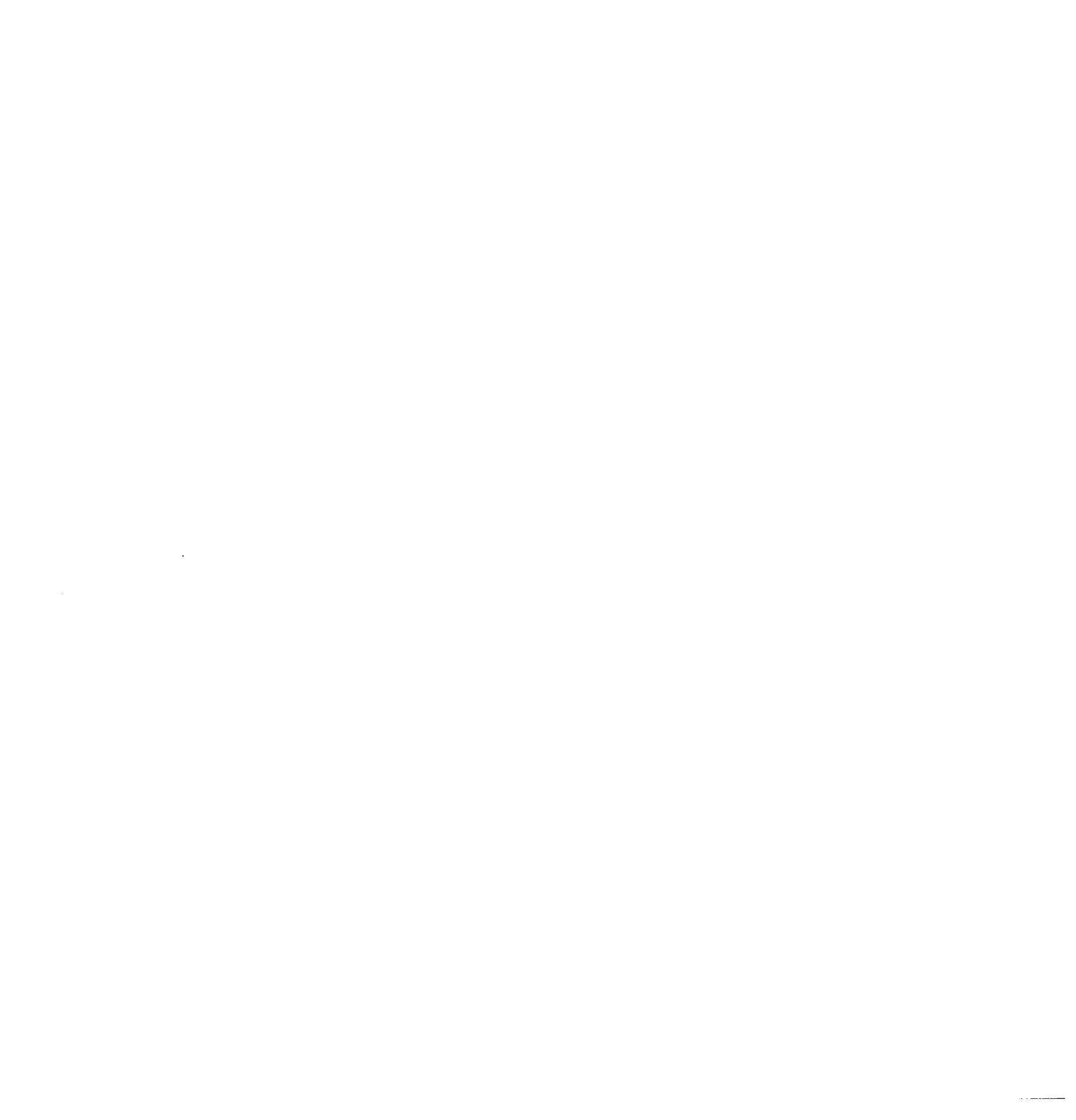